\title{
The Killability of Fish in The Sims 3: Pets and Stardew Valley
}

\author{
Erik van Ooijen ${ }^{1}$
}

Received: 18 January 2018/ Accepted: 26 March 2018/Published online: 11 May 2018

(C) The Author(s) 2018

\begin{abstract}
The article considers video games as procedural arguments on the killability and nonkillability of nonhuman animal species, especially marine animals. It focuses on what acts of violence are made possible in games, and against whom. It argues that shifting the critical perspective from killing to killability allows us to study the implicit violence found in "nonviolent" or "friendly" games that usually garner little controversy. Two games that both set out to avoid animal violence, and even promote animal care, are studied: Maxis' The Sims 3: Pets (2011) and ConcernedApe's Stardew Valley (2016). The study considers how these games construct a hierarchy of classes of animals that are either included in, or excluded from, the realm of moral concern. Thus, the games are seen as models of how similar hierarchies are created in the real world of so-called "meat culture". Most significantly, the study demonstrates how fish is a prime example of a class of animals that is removed from the realm of moral concern, even in supposedly ethical and animalfriendly games.
\end{abstract}

Keywords Killability · Animal violence $\cdot$ Meat in games · Fishing · Procedural rhetoric

\section{Introduction}

The article considers computer games as arguments on the killability and nonkillability of nonhuman animal species, especially marine animals. The idea of computer games as arguments is inspired by what media scholar Ian Bogost calls

Erik van Ooijen

erik.vanooijen@kau.se

$1 \quad \mathrm{KuFo}$ (The Research Group for Culture Studies), Department of Language, Literature and Intercultural Studies, Karlstad University, Karlstad, Sweden 
the procedural rhetoric of games. According to Bogost (2007), games explain "processes with other processes" (p. 9). When a game implements the computational representation of a cultural process, the way it does so presents an implicit understanding of how that particular process works, according to what logic it operates, and how it should be carried out in practice. The way a game presents processes related to soccer or nuclear war says something about how soccer or nuclear war is thought to function; the way a game implements processes of eating says something about how eating is to be carried out, in relation to what foods, in what context, and for what reason, et cetera. In this way, virtual games can be said to "make arguments about the way systems work in the material world" (Bogost 2007, p. 47).

The games taken into consideration are Maxis' major title The Sims 3: Pets (2011) and ConcernedApe's indie title Stardew Valley (2016). These games seldom occur in debates on games and violence, since they come neither from the class of ultra-violent games mostly berated for their gratuitous reveling in gory depictions (such as Rockstar's GTA- or Manhunt-series), nor from the class of games consciously using violence to address moral and philosophical concerns (such as 2K's lauded Bioshock-games). Shifting the critical perspective from killing to killability allows us to study the implicit violence found in "nonviolent" or "friendly" games that usually garner little controversy. A benefit of this is that it helps us to move past the level of provocative imagery, to rather get down to the underlying structures through which games produce meaning.

\section{Killability and the Making Possible of Violence}

Like all media, computer games often represent acts of violence. What distinguishes games from other media is that they must determine how and under what circumstances player-initiated acts of violence are allowed, in relation to what classes of objects, and for what reasons. In his book on "gamer theory", media scholar McKenzie Wark (2007) points out how the primary violence of games is found, not in any particular representation of violent events, but in the way each particular game must decide on "where everything belongs and how it is ranked" ( $\S$ 23). In Wark's words: "The real violence of gamespace is its dicing of everything analog into the digital, cutting continuums into bits." (\$ 23) In creating a game world and its associated gameplay, game designers must decide on, not only what may exist in that world, but also how everything existing should be organized into various classes, associated with certain implicit and explicit values and affordances, or possibilities for interaction. Each thing or individual must be sorted into a specific class associated with actions that are considered proper or improper for that class.

Before an act of violence may be carried out in a game, then, it must be decided what classes of objects are open to violence in the first place. For example, in some war games, you are allowed to kill enemy soldiers but not your own companions; in others, you may kill any soldier but no civilian. Many games make a sharp distinction between nonplayer characters that belong to the narrative, and those that are part of the world as a kind of setting. In Rockstar's infamous Grand Theft Auto- 
series, for example, you may kill all kinds of randomized "pedestrians" roaming around the streets with little to no consequence, but the characters who are necessary for the story to progress may only be killed when and if the narrative allows it. In Obsidian's Fallout: New Vegas (2010), on the other hand, you may kill just about anybody, whether they are of importance for the plot or not. But even here a rather arbitrary exception is made in that you cannot kill children (that is, any member belonging to the class marked as children). Such decisions and restrictions display an underlying moral evaluation regarding whom should be exposed to, or exempt from, violence; it separates the taboo from the fair game.

In analyzing a game, we may concentrate either on depictions of violence as they appear in the narrative story arc of the game, or on its underlying principles of organization. By focusing, not on the individual act of violence, but on how acts of violence are made possible at the structural level, we shift our perspective from the question of whom is getting killed to whom is made killable. The concept of killability is used in critical animal studies to determine how and under what circumstances it is considered acceptable, or is even encouraged, to kill a living being. Killability makes visible which beings are considered proper individuals, and which are reduced to mere things. The concept goes back to Donna Haraway's (2008) understanding of Jacques Derrida's deconstruction of the logic of sacrifice as the postulation of "a whole world of those who can be killed, because finally they are only something, not somebody" (p. 79). But whereas Haraway considers it a "misstep to separate the world's beings into those who may be killed and those who may not" (p. 79), this is precisely what game designers must do in constructing a game world. Since game worlds are digital rather than analog from the start, such separations form the very basis of its reality.

Fundamentally, computer games can be studied as models of how classes are made killable.

\subsection{Nonkillability in The Sims 3: Pets}

Consider now the ways in which different species are distinguished in Maxis' childfriendly Sims 3. The Sims is a series of whimsical life simulators where you govern the daily lives of the members of a household: you tend to their needs (eating, sleeping, going to the toilet, having company, and so on) as well as their individual wishes and desires (progressing in their career, finding love, buying consumer goods, meeting new friends, et cetera). Although your characters may die, from old age or in an accident, the game is mostly free from violence; an angry sim may certainly slap, or even engage in a cartoonish fight with, another sim, but you can never inflict serious pain or murder another sim. Whereas sims are mortal, they are not killable in Haraway's sense.

This holds true also for the various nonhuman animals added to the game in its Pets (2011) expansion. These animals may be grouped into a few different classes depending on how the player may interact with them. First of all you have the pets proper: these are dogs, cats, and horses that actually are controllable by the player and constitute full members of your household. In terms of gameplay they function as slimmed down versions of human characters: the pets are granted agency and 
subjectivity, and they have personalities and preferences of their own, as well as wills and wishes to fulfill. During the progress of the game, they will develop personal traits and gain new skills, and develop close emotional bonds to other pets as well as their human caretakers. Proper pethood in the game, then, comes close to what Haraway (2008) calls the middle-class "human-animal companionate family" (p. 47). Functioning as parts of an already formed family, without the possibility to create a "household" of their own, the game represents pets as reduced and slightly altered versions of human subjects, lacking the more advanced capabilities of their human caretakers, while retaining a sense of subjectivity, individuality and freedom. Although they are necessarily "owned" by a human sim, they exhibit an amount of agency similar to that of their caretaker.

In addition to the pets proper, there are also minor pets, which function as passive collectibles: these are various lizards, snakes, rodents, turtles, birds, and fish. They cannot be played and are not considered as members of the household, but rather constitute a special group of collectible possessions. The only way to interact with them is to capture them in the wild and keep them in cages or terrariums. Lacking agency and desires of their own, they must be fed by their human caretakers or they will die. And still, neither the proper nor the minor pets are made killable; like human sims, they display mortality without killability.

A third category contains wild animals, such as bigger birds or wild cats, that must be befriended by the human character in order to become domesticated pets. Some species remain in the wild, however, and may neither be taken into the house nor the household. They may be petted in the wild, but never domesticated. Deer and raccoons, for instance, constitute opportunities for a kind of "wildlife experiences", but they also function as pests: while raccoons will knock over your garbage can, spilling out the waste, deer will eat all the carefully grown vegetables in your garden. Yet, while annoying, even pests are exempted from killability: they may be shooed away, but they may not be hunted or killed.

\subsection{Killability in The Sims 3: Pets}

On the whole, Sims 3 prevents violence in general, and violence against animals in particular. As have been pointed out elsewhere (Ooijen 2015), the game goes to such lengths in avoiding representations of the killing of animals that all meat products your sims may cook and eat are grown, like plants. Rather than butchering animals for their meat, you harvest steaks and burger patties from your garden. There is, however, one flagrant exception to this rule of nonviolence: fish. Human sims may fish in ponds and oceans, and while the catch may be kept as minor pets in aquariums, it may also be cooked and eaten. Fish, in other words, are the only type of animal to be made killable in the game. They can even be used as fertilizer when growing your crops, thus reintroducing dead animals into the game's cycle of meat production: whereas steaks grow on plants like any other fruit or vegetable, these plants grow out of the bodies of decomposing marine animals. Somewhat contradictory, the game seems to assert that you should avoid violence against animals, while maintaining that fish are not animals. 
By implementing this exception, the game seems to argue, implicitly, that fish are to be expelled from the circle of moral concern. If pets are rendered less than human by the game, and minor pets are rendered less than pets, fish are rendered even less than animals, and finally made killable. Using a concept from gender scholar Tara Mehrabi (2016), we may say that Sims 3 enacts fish as "the threshold of killability" (p. 182). In Mehrabi's words, "the spectrum of killability narrows down and pushes the threshold of killability, from human to animal and from bigger animals to smaller animals such as mice, then invertebrates and organic matter" (p. 184).

By enacting fish as the threshold of killability, Sims 3 models a common indifference towards fish found within society at large. Seldom are concerns raised against the killing of fish, whereas violence against pets often cause public uproar. Why do we not care about fish? In describing what she calls "meat culture", cultural scholar Annie Potts (2016) points out how the very strangeness of fish, when considered from a human point of view, locates them at the far end of the ethical spectrum: "They are viewed as so different to humans that they have commonly been disregarded as sentient creatures." (p. 11).

Sims 3 constructs an implicit model of such hierarchies, by grading animals from those who are close to us, in terms of emotional and psychological likeness (cats, dogs), to those that are too small and too strange to be apprehended as anything other than "just animals" (lizards, rodents), to those that are not even granted the status of animality or life at all. It is almost as if the fish never were alive in the first place; as if they were literal frutti di mare plucked from the sea. Were you to raise cattle in a game like the Sims, you would actively have to slaughter them by some kind of action in order to turn the animal into meat, and, thus, food. Fish, on the other hand, you simply pick out of the water, without ever having to actively perform a killing interaction. You sink your line, reel it in, and suddenly have a fish in your inventory. This item constitutes a kind of "Schrödinger's fish", always in an undecidable state between life and death. Since you may put it in an aquarium, it must still be alive; but since you may also put it in a frying pan (for food) or in the ground (for fertilizer), it must already be dead.

Potts (2016) points out how the flesh from fish and other marine animals often is regarded as nonmeat. For example, during a dinner, fish may be served as an "alternative" to meat, and sometimes even be eaten by self-proclaimed vegetarians. Interestingly enough, Sims 3 acknowledges the meatiness of fish by making characters endowed with the trait Vegetarian react to dishes containing fish by becoming nauseated, as they would to any other kind of meat. Nevertheless, the special status attributed to fish prompts us to ask why it is considered killable. Perhaps, this is due to the aquatic nature of fish, allowing them to be killed passively. The player never have to perform the kill, but simply may pull the fish out of the water. It is almost as if the fish never died, even at the point of certain death. Death becomes a lack of violence, a nonevent caused by a nonaction. 


\section{Killability in Stardew Valley}

The moral exception regarding fish is the more striking the more a game strives to convey a concern for animal care. ConcernedApe's Stardew Valley is an acclaimed retro-themed and independently developed farming simulator created by one-man developer Eric Barone. In the game, the player character moves out from the city to get a small, rundown farm going again, while also adjusting to the rural community of the titular town. You take part in social community events, and engage with the small town residents, while expanding your farm, growing and harvesting crops, raising livestock, and so on. You have a pet-a cat or a dog-which you may pet and provide with water. This is the only way to interact with this pet.

In an interview, Barone has stated that he did not only want the game to be fun but also "have real-world messages" (Singal 2016). The game, in other words, is explicitly constructed to present an argument, made manifest by the conscious design decision to exclude processes of butchering from the game. Whereas you may keep chicken, ducks, cows, sheep, pigs, and so on, you cannot kill, eat, or cook these animals. Instead, you harvest them for eggs, milk, wool, et cetera, which then may be turned into products like cheese or dishes like pancakes and omelets. For the animals to be productive, you need to take constant care of them, keeping them safe, and socializing with them. Through these mechanics, the game encourages you to develop a close emotional bond with your animals through a "friendship" system measured in hearts.

According to the game designer, the animal friendly ambition would go against the option to kill them for meat. As Barone states in the interview:

I didn't want to have that sort of violence. You give the animals names, pet them, and a little heart goes above their head and stuff, and then you butcher them? [...] It just felt wrong. It didn't jibe with the feeling I was going for with the game, so I cut that, and I don't regret it. (Singal 2016)

According to the procedural logic of the game, meat is consequently not part of the farming economy. You do not keep livestock for meat but for other products: whereas cows provide milk, pigs produce truffles rather than pork. Among the 70 or so different recipes the player may cook in the game, not one contains meat. Yet, once again, there is a blatant exception. Using fishing rods or crab pots, the player may catch a large number of aquatic species (such as squid, tuna, eel) which then may be cooked into dishes like calamari, sushi, or fish soup. In Stardew Valley, too, fish are enacted as the threshold of killability.

Fish, however, are not the only class of beings made killable in the game. Bugs, for example, may be killed, providing the player with bug meat that can be turned into fish bait. As demonstrated by this example, there is yet another class of beings, situated even further down on the spectrum of killability, namely the "monsters". As Jeffrey Jerome Cohen (1996) states in his theses on monster culture, the monster "dwells at the gates of difference"; it is "difference made flesh", incorporated precisely by being enacted as the Other, that is, as far removed from the self (p. 7). Labelling a group of individuals as monstrous has always been a strategy for making them killable. In Stardew Valley, monsters dwell in remote and enclosed places like 
mines and caverns, which the player must invade in pursuit of treasure and resources. If farm animals invite friendly interactions like petting and feeding, monsters can only be interacted with through violence: unless they are killed, they will hurt and possibly kill the player character. Among these monsters are fantastic creatures, like ghosts and slimes, but also natural animal species, like bugs, bats, and grubs. Unlike livestock, their bodies may be used for crafting, for instance by turning bug meat into fish bait. If livestock provide the player with resources, monsters are resources. And if fish are killed passively (like in The Sims), monsters must be killed actively, by actually performing acts of violence. Thus, violence against animals is not only allowed, but encouraged.

Although Stardew Valley sets out to avoid animal violence, and even promote an ethics of animal care, the way it categorizes species into different classes associated with different processes of gameplay nevertheless provides the player with a clear limit for that care. While some species are taken into the realm of moral concern, others are excluded. Or, using Haraway's expression: the game world is clearly divided into "those who may be killed and those who may not".

\section{Conclusion}

Computer games provide us with useful models for studying how different species are evaluated, in relation to each other and to us. In this sense, they help us make explicit the often implicit spectrum of killability pervading our meat culture. By focusing on processes of killability while studying games, rather than on violent representations per se, we have noticed how even "friendly" games, that set out to avoid violence against animals, tend to construct classes of certain animal species as open to killing. As has been demonstrated, fish is a prime example of a class of animals that are removed from the realm of moral concern, even in supposedly ethical and animal-friendly games.

By enacting fish as the threshold of killability, these games present procedural arguments in favor of the vast exploitation of marine life marking late industrial capitalism. Each year, humans pull 2.7 trillion marine animals out of the seas and oceans (Potts 2016). In addition to this, industrial fish farms produce another 66 million tons of fish. This aquatic massacre is possible precisely due to the ways in which our society makes fish killable. Like all cultural objects, computer games are part of this process.

\section{Compliance with Ethical Standards}

Conflict of interest On behalf of all authors, the corresponding author states that there is no conflict of interest.

Open Access This article is distributed under the terms of the Creative Commons Attribution 4.0 International License (http://creativecommons.org/licenses/by/4.0/), which permits unrestricted use, distribution, and reproduction in any medium, provided you give appropriate credit to the original author(s) and the source, provide a link to the Creative Commons license, and indicate if changes were made. 


\section{References}

Bogost, I. (2007). Persuasive games: The expressive power of videogames. Cambridge, MA: MIT Press. Cohen, J. (1996). Monster culture (seven theses). In J. Cohen (Ed.), Monster theory: Reading culture (pp. 3-25). Minneapolis: University of Minnesota Press.

Haraway, D. (2008). When species meet. Minneapolis: University of Minnesota Press.

Mehrabi, T. (2016). Making death matter: A feminist technoscience study of Alzheimer's sciences in the laboratory. Linköping: Linköping University.

Ooijen, E. V. (2015). Att äta digitala djur: Spel, våld och ideologi. Tidskrift för litteraturvetenskap, 4, $29-41$.

Potts, A. (2016). What is meat culture? In A. Potts (Ed.), Meat culture (pp. 1-30). Leiden: Brill.

Singal, J. (2016). How a first-time developer created Stardew Valley, 2016's best game to date. Vulture. http://www.vulture.com/2016/03/first-time-developer-made-stardew-valley.html. Accessed January $18,2018$.

Wark, M. (2007). Gamer theory. Cambridge, MA: Harvard University Press. 